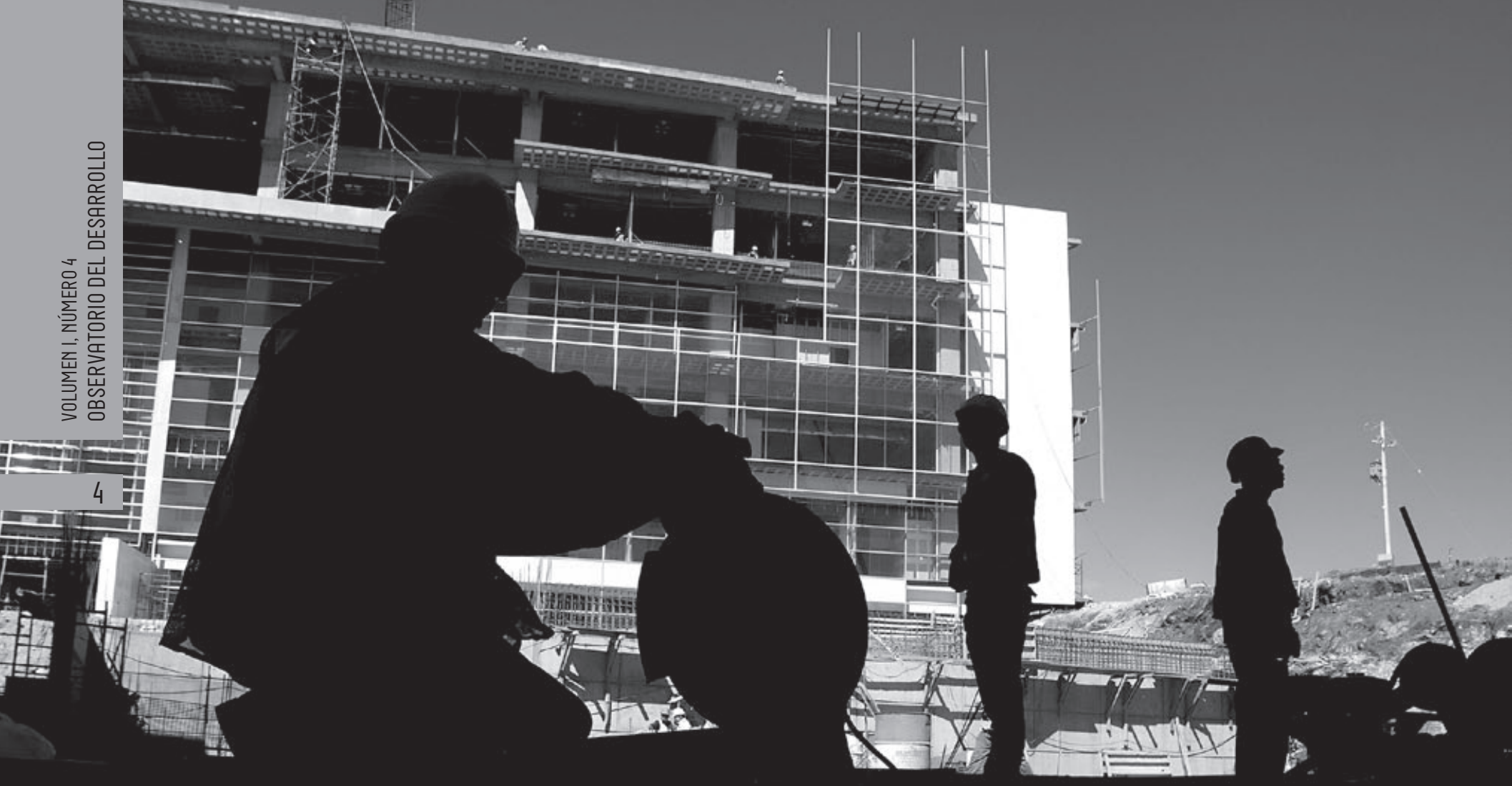

\title{
Gobernanza asimétrica, normas laborales y derechos de los migrantes
}

El establecimiento de un modelo viable para la codificación e institucionalización de normas laborales, derechos humanos y derechos de los migrantes no puede dejarse en manos del actual régimen de gobernanza global asimétrica. A nivel mundial y regional, las confederaciones sindicales y otras organizaciones de la sociedad civil (OSC) tienen un papel central para reposicionar la temática de los derechos y el desarrollo en el terreno de una globalización justa. Este artículo aborda la rendición de cuentas $y$ las contingencias para aplicar los derechos humanos, laborales y de los migrantes y la Agenda de Trabajo Decente de la Organización Internacional del Trabajo (OIT) dentro de la arquitectura de la gobernanza global.

\section{Branka Likic-Brboric Cart-Ulrik Schierup}

(traducción del inglés de Luis Rodolfo Morán Quiroz) 


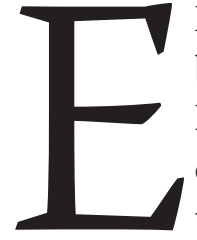
l surgimiento de un régimen de mercado laboral global, reconfigurado durante las últimas tres décadas, se ha caracterizado por una creciente informalización del empleo y tiene como corolario condiciones precarias de trabajo; los más afectados han sido los migrantes irregulares. Hasta la fecha, los procesos de globalización se han dirigido hacia la «acumulación por despojo», ${ }^{1}$ y han implicado una marcada reducción de los derechos laborales ${ }^{2}$ y re-mercantilización de la fuerza de trabajo. ${ }^{3}$ Una gama de movimientos sociales y políticos en los ámbitos transnacional, regional y nacional ha generado estrategias y discursos contestatarios que enfatizan la prominencia de los derechos universales y colectivos.

\section{RÉGIMEN DE GOBERNANZA GLOBAL EMERGENTE, «GLOBALIZACIÓN JUSTA»Y «AGENDA DE TRABAJO DECENTE»}

La gobernanza global ha sido definida como «el conjunto normativo, social, legal, institucional y otros procesos y normas, que configuran y, en algunos casos, regulan y controlan el interjuego dialéctico de la globalización y la fragmentación», implicando una gama de actores estatales y no estatales. ${ }^{4}$ Sin duda alguna, el sistema de gobernanza global y su agenda han estado configurados, primordialmente, por los países más poderosos y económicamente avanzados, la Organización para la Cooperación y el Desarrollo Económicos (OCDE), la organización de los países más desarrollados encabezada por el grupo de los siete (G7) y claramente dominada por Estados Unidos, así como por las corporaciones transnacionales.

Los principales actores de la gobernanza global han conducido, de manera primordial y sistemática, al proceso de globalización hacia la creación de un régimen liberal de comercio y un correlativo sistema financiero y monetario. Esto ha encarnado en el establecimiento de la Organización Mundial del Comercio (OMC), posterior a la Ronda de Uruguay. En los procesos de negociación que rodean el establecimiento del actual régimen global de comercio, la propia gobernanza global se ha reconfigurado. Las instituciones financieras internacionales (IFI) de Bretton Woods, a saber, el Banco Mundial (BM) y el Fondo Monetario Internacional (FMI), han jugado un papel decisivo en la imposición del modelo neoliberal y la promoción de la libre movilidad del capital. Apoyadas fuertemente por Estados Unidos y las economías avanzadas, las IFI han ocupado una posición exclusiva, aparte del resto de la arquitectura organizacional de la Organización de las Naciones Unidas (ONU), y reciben un mandato claro y los recursos necesarios para promover la gobernanza económica global jerárquica, aislada de quejas democráticas.

Sin embargo, al inicio del milenio, el «paradigma de Bretton Woods» y su optimismo respecto a la erradicación de la pobreza a través de la adopción, por los países en desarrollo, del régimen co- mercial internacional impulsado por el GATT/OMC, ${ }^{5}$ ha sido cada vez más cuestionado. Una alternativa, «el paradigma de la ONU», ${ }^{6}$ basada en una concepción diferente del nexo entre liberalización global y pobreza, inequidad, deterioro de las condiciones sociales, derechos humanos y laborales, ha sido presentada por varios fondos, comisiones y agencias afiliados a un plan complejo y desarticulado de la onu bajo el mecanismo de coordinación del Consejo Económico y Social (ECOSOC, por sus siglas en inglés). Éste incluye al Programa de Naciones Unidad para el Desarrollo (PNUD), la Organización Internacional del Trabajo (ОІт), el Fondo de Naciones Unidas para la Infancia (UNICEF, por sus siglas en inglés) y la Oficina del Alto Comisionado para los Derechos Humanos (OACDH) en colaboración con la Organización Internacional para la Migración (OIM). Durante la década de los noventa, estas agencias multilaterales, dentro de sus mandatos superpue ${ }^{\circ}$ stos de promover el desarrollo humano, los derechos laborales y la justicia social, elaboraron un amplio marco teórico y normativo para la promoción de la dimensión social de la globalización.

Una discusión sobre las normas laborales internacionales, diseñada y supervisada por la OIT, ha desempeñado un importante papel en este discurso alternativo sobre la globalización, especialmente tras el establecimiento de la OMC. Con el fin de abordar el desecenso repetido respecto a la inclusión de cláusulas sociales en las negociaciones de la OMC, y la exclusión de la OIT de estas negociaciones, la Asamblea General de la ONU decidió, empero, en junio de 2000 , comisionar a la oit la tarea de formular una estrategia incluyente de empleo global. La OIT, dada la oportunidad dorada para restaurar su deteriorada posición en el marco de la gobernanza global, reafirmó su mandato de promover la justicia social mediante la confección de una «Agenda de Trabajo Decente» (ATD), formulada por su director general, Juan Samovia, en un informe sobre el trabajo decente publicado en 1999.7 
Según ese informe, la principal meta de la OIT es "promover oportunidades para que las mujeres y los hombres consigan un empleo decente y productivo, en condiciones de libertad, igualdad, seguridad y dignidad». ${ }^{8}$ La ATD corroboró el principio básico de la Constitución de la oit. Ésta establece la «des-mercantilización» de la fuerza de trabajo y reafirma la Declaración sobre los Principios y Derechos Fundamentales en el Trabajo que data de 1998. La declaración afirmaba ocho convenciones centrales que aseguraban la libertad de asociación, el reconocimiento de la negociación colectiva, la eliminación del trabajo forzado, la prohibición de trabajo de menores, la eliminación de la discriminación en el empleo y en la ocupación, y el derecho a un ingreso. Estos derechos también están vinculados con la Declaración Universal de los Derechos Humanos de 1948, el Acuerdo Internacional de los Derechos Económicos, Sociales y Culturales de 1966 y la Declaración y Compromisos de la Cumbre Social Mundial de 1995.

Además de estas ambiciosas metas y estrategias, la ATD va más allá de la afirmación de una base social universal de la globalización económica y abre un diálogo con los movimientos sociales y las ONG globales. ${ }^{9}$ El informe Decent Work and the Informal Economy ${ }^{10}$ es uno de los informes más significativos y provocadores. Su preparación y apoyo implicaron acalorados debates entre académicos, activistas feministas, ONG, así como sindicatos, gobiernos y empleadores. ${ }^{11}$ De acuerdo con éste, la OIT definió su meta como la promoción del «trabajo decente a lo largo de todo el continuo de la informal a la formalidad de la economía, con medidas orientadas al desarrollo, la reducción de la pobreza y la equidad para los géneros». ${ }^{12}$

Al impulsar estas metas estratégicas y el objetivo organizacional más amplio de reinventarse como el principal foro para el diálogo sobre la política social, la OIT generó otras iniciativas globales. Ha logrado estructurar un discurso de justicia global, solidaridad y globalización justa, configurado en torno al concepto de trabajo decente, marcos cognitivos y normativos en apoyo de políticas alternativas dirigidas a la reconfiguración discursiva del orden global. En el nivel más alto, la oit lanzó la Comisión Mundial sobre la Dimensión Social de la Globalización (WCSDG, por sus siglas en inglés) que produjo un reporte final en 2004, A Fair Globalization. ${ }^{13}$

Otra iniciativa refiere a la migración como un fenómeno global de creciente importancia y a la construcción del Grupo de Migración Global (GMG) junto a la oim y varias otras agencias que complementan las iniciativas de la ONU en el campo de la migración. El secretario general de la ONU también lanzó la Comisión Mundial sobre Migraciones Internacionales (CMMI) que presentó su informe en 2005. ${ }^{14}$ En 2006, el Diálogo de Alto Nivel sobre Migración y Desarrollo de la ONU apoyó el proceso global de consulta informal impulsado por los gobiernos del Foro Global sobre Migración y Desarrollo (FGMD) con el propósito de promover marcos compartidos de políticas en el campo de la migración. De manera concomitante a esta acción, la OIT inició la elaboración de un «marco multilateral no limitante para un enfoque sobre la migración laboral basado en derechos y el establecimiento de un diálogo sobre la migración en asociación con las organizaciones internacionales y multilaterales», publicado en 2010. ${ }^{15}$

\section{GRANDES PALABRAS, BAJO IMPACTO REAL}

Sin embargo, las declaraciones universales, las convenciones y recomendaciones de la ONU y la OIT, en gran medida, han demostrado ser insuficientes, ya que no han estado respaldadas por sanciones efectivas. El caso más conspicuo de falta de voluntad política para proteger los derechos de los trabajadores migrantes lo constituye el hecho de que la Convención de los Trabajadores Migrantes se iniciara en 1980, se adoptara en 1990 y comenzara a ser ratificado en 1998, para posteriormente entrar en vigor en 2003 después de que treinta países, en su mayoría países de origen de migrantes, lo habían ratificado. Por el contrario, hemos visto un giro hacia la «securitización» de los regímenes de migración enfocada en la construcción de mecanismos de control fronterizo. Además, la evidencia ha confirmado la regresión, asociada con el comercio, de las normas laborales y de los derechos de los trabajadores migrantes, sobre todo en las industrias de exportación que requieren una fuerza de trabajo intensiva y de baja calificación, tanto en economías en desarrollo como en las avanzadas. ${ }^{16}$

Se han identificado varias explicaciones importantes sobre el bajo impacto real de los derechos humanos, las normas laborales y la ATD: un enorme conjunto de documentos, informes y normas sin impacto real; la falta de capacidad organizacional, de legitimidad y poder político de los principales actores (las instituciones basadas en la OIT y la ONU, sindicatos, ONG) para promover la agenda y la competencia organizacional por 
la legitimidad; la ATD ha estado apoyada formalmente pero no ha sido aplicada por los gobiernos; éstos no han adoptado un enfoque coherente e integrado de políticas.

Así, aun cuando este paradigma alternativo de la ONU sobre el desarrollo y la globalización ha sido tomado en cuenta por los actores más poderosos - G20, Unión Europea (UE), BM y FMI- la gobernanza global emergente ha estado marcada, y todavía lo está, por un marcado dualismo asimétrico. Este dualismo refleja las asimetrías normativas que dimanan del neoliberalismo y la asociada subordinación de la gobernanza global a la supremacía de un régimen de libre comercio y al canon del libre movimiento del capital.

Esto nos conduce a la falta efectiva de rendición de cuentas de un régimen de gobernanza global y la necesidad de poner en práctica una rendición de cuentas inclusiva que indica el requisito democrático de que los representantes deban rendir cuentas «ante todos los que están sujetos a sus decisiones». ${ }^{17}$ De modo que la cuestión de la «rendición de cuentas inclusiva», incluso ante los no ciudadanos que carecen de representación política, puede traducirse en un asunto que remite a los mecanismos e instrumentos que podrían garantizar la rendición de cuentas de todos los que toman las decisiones. Esta concepción de la rendición de cuentas, afirma Lafont, podría también abordar el evidente fracaso de un enfoque estadocéntrico sobre los derechos humanos para concebir la responsabilidad de los actores no estatales (corporaciones transnacionales y organismos multilaterales como la OMC, BM y FMI) en cuanto a la protección y respeto de los derechos humanos indivisibles. ${ }^{18} \mathrm{El}$ establecimiento de un modelo realizable para la codificación y la institucionalización, al reconceptualizar los derechos humanos en términos de una política social global de rendición de cuentas, con los derechos de los migrantes y los derechos laborales como pilares esenciales, no puede dejarse al actual régimen de gobernanza global asimétrica, ni a la iniciativa de los gobiernos nacionales interesados, ni a organismos regionales como la UE o el Tratado de Libre Comercio de América del Norte (TLCAN). Difícilmente se logrará sin ser impulsado y fundamentado en un contramovimiento social variopinto opuesto a la globalización neoliberal.

\section{SindicAtos, ONG Y MOVIMIENTOS SOCIALES}

Se pueden identificar varias rutas de instrumentación en los procesos relacionados con la promoción de la
ATD y los derechos de los trabajadores migrantes: ${ }^{19}$ a) cabildeo y defensa de la ratificación y realización de la ATD, normas laborales centrales y convenciones y recomendaciones específicas para los migrantes; $b$ ) promoción de normas laborales y de las cláusulas sociales por medio de instrumentos relacionados con el comercio, como los acuerdos comerciales unilaterales, bilaterales y regionales; c) códigos de conducta voluntarios y de responsabilidad social corporativa (CRS).

Las prácticas mencionadas anteriormente para responder a las demandas por garantizar los derechos humanos globales, la ATD y los derechos de los migrantes tienen dos rasgos en común: la falta de aplicación y ejecución, por un lado, pero, por el otro, su potencial movilizador. ${ }^{20}$

Se han seguido básicamente dos vías de acción: una dirigida al empoderamiento del "precariado», un término utilizado aquí para denotar una fuerza de trabajo desechable, sin derechos y seguridad básicas; y otra que tiene que ver con la gobernanza de la cadena productiva de valor, donde el papel de las agencias multilaterales, las corporaciones transnacionales y el Estado queda enfocado. Respecto a la primera, se ha generado una división entre los sindicatos y las ONG. Los sindicatos, por un lado, fueron criticados por su estilo burocrático, por su nacionalismo y por excluir a quienes estaban en la situación más precaria en términos de ciudadanía y en su posición en el mercado laboral, mientras que se les alabó por su capacidad organizativa y su democracia interna. ${ }^{21} \mathrm{Sin}$ embargo, la movilización de los sindicatos en contra de la criminalización de los inmigrantes ilegales en redadas en Estados Unidos y en varios países europeos apunta hacia un cambio en las prácticas y actitudes de los sindicatos.

En 2006, la ATD probó haber jugado un papel importante como plataforma común para la unificación y consolidación de la Confederación Internacional de Sindicatos (ITUC, por sus siglas en inglés). La promoción de la ATD ha mejorado la capacidad organizativa de los sindicatos en múltiples niveles para actuar tanto local como globalmente y para desarrollar nuevas formas de movilización y de alianzas con las organizaciones de la sociedad civil.22 Además, los nuevos movimientos sociales laborales internacionales y su movilización a favor de los derechos de los migrantes también han proliferado tanto en el nivel local como en el transnacional, generando la esperanza de un «contramovimiento» global. ${ }^{23}$

Las ONG, por otra parte, fueron elogiadas por su organización flexible al tiempo que se les criticaba la falta 
de coordinación y el enfocarse en la reducción de la pobreza, dejando de lado el tema del empleo. ${ }^{24}$ Sin embargo, los temas de empleo y condiciones de trabajo han sido abordados, por ejemplo, por la red de investigación WIEGO en el manual de políticas Mainstreaming Informal Employment and Gender in Poverty Reduction. ${ }^{25}$ Otra iniciativa fue lanzada por la Plataforma para la Cooperación Internacional sobre Migrantes Internacionales (PICUM, por sus siglas en inglés), una ONG abarcadora ubicada en Bruselas. El informe Ten Ways to Protect Undocumented Migrant Workers ${ }^{26}$ convoca a la participación cívica y sindical en la promoción de los derechos humanos y laborales de los trabajadores migrantes indocumentados, y su empoderamiento a través de una reformulación de las políticas de integración de la UE y la Estrategia Europea de Inclusión Social. Recientemente, la ATD fue lanzada como la principal plataforma de Solidar, una red europea de cincuenta y dos ONG de veinticinco países que lucha a favor de la Europa Social, los derechos laborales y los migrantes.

Finalmente, pero no menos importante, la ATD desempeñó un papel prominente en la movilización de los migrantes en el trabajo preparatorio que precedió a la reunión del Foro Global de Migración y Desarrollo (FMMD) en 2008. El informe señala que un enfoque sobre la migración basado en los derechos no únicamente está dirigido a aquéllos «relacionados con los migrantes y la migración, sino también hacia principios más amplios como el derecho al desarrollo y la agenda del trabajo decente. La meta de ese enfoque es asegurar un desarrollo sustentable a la vez que evitar la explotación de quienes se trasladan a vivir y trabajar en el extranjero». ${ }^{27}$ Junto con la promoción de los derechos de los trabajadores migrantes, se ha re- conocido la importancia de organizar e incluir a los propios migrantes en el debate del desarrollo. ${ }^{28}$ De hecho, la apertura y pluralidad de la red Acción Global de los Pueblos sobre Migración, Desarrollo y Derechos Humanos (AGP), junto con la movilización transnacional basada en una fuerte perspectiva crítica hacia la globalización neoliberal, podría evitar la posibilidad de cooptar el tedioso trabajo preparatorio para reubicar el nexo entre migración y desarrollo y, con ello, ayudar a detener nuestra actual oleada de mercantilización y precarización de la fuerza de trabajo.

Sin embargo, con todo el entusiasmo que entraña la movilización social, cabe ejercer una dosis de cautela. Según lo expresa Michael Burawoy: ${ }^{29}$

al optimismo actual tiene que contraponerse un pesimismo despiadado, no un alarmismo sino un análisis cuidadoso y detallado de la manera en que el capitalismo combina la mercantilización de la naturaleza, el dinero y la fuerza de trabajo, y con ello destruye la misma base desde la cual podría construirse un «contramovimiento».

\section{Notas}

1 David Harvey, A Brief History of Neoliberalism, Oxford, Oxford University Press, 2005.

2 Shareen Hertel, Human Rights and the Global Economy, Bringing Labor Rights, 2009.

3 Theo Papadopoulos, «The Recommodification of European Labour: Theoretical and Empirical Explorations», Working Paper Series WP-05-03, 2005, disponible en 〈http://www.bath.ac.uk/eri/ERIworking-papers/ERI-working-paper-05-03-final.pdf >, consultado el 5/10/2011.

4 John Clarke y Geoffrey Edwards, «Introduction» en Jonh Clarke y Geoffrey Edwards (editores), Global Governance in the Twenty-First Century, Houndmills, Basingstoke y Nueva York, Palgrave MacMillan, 2004, p 6.
5 Jean-Philippe Thérien, «Beyond the NorthSouth Divide: The Two Tales of World Poverty» en R. Wilkinson (editor), The Global Governance Reader, Londres, Routledge, Taylor and Francis Group, 2005.

6 Jean-Philippe Thérien, op. cit.

7 Organización Mundial del Trabajo (OIT), Decent Work: Report of the Director-General to the 87 th Session of the International Labour Conference, Ginebra, 1999.

8 Idem. 


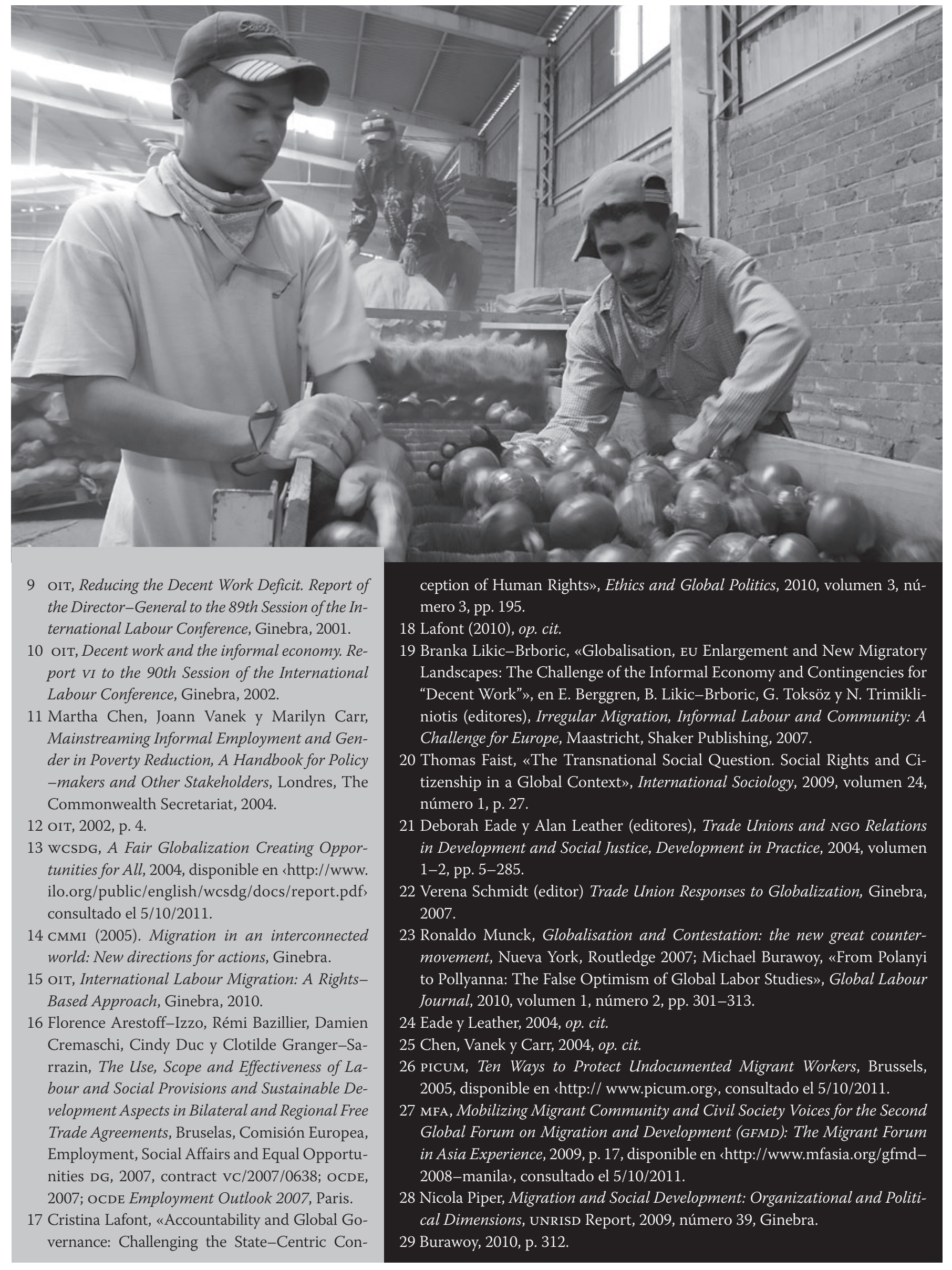

